\title{
Epileptic Personality Changes and Their Therapy
}

\author{
Aliyev $\mathrm{NA}^{1, *}$, Aliyev $\mathrm{ZN}^{2}$, and Aliyeva $\mathrm{SE}^{3}$ \\ ${ }^{1}$ Department of Psychiatry and Drug Addiction1, Baku, Azerbaijan \\ ${ }^{2}$ Azerbaijan Medical University, Department of Psychiatry, Azerbaijan \\ ${ }^{3}$ Azerbaijan Medical University, Department of Neurology, Baku, Azerbaijan
}

*Corresponding author: Aliyev NA, Azerbaijan State Institute for the Improvement of Doctors named after A. Aliyev, Department of Psychiatry and Drug Addiction, Baku, Azerbaijan, E-mail: aliyevnadir@yahoo.com

Received: 16 Mar, 2020 | Accepted: 01 Apr, 2020 | Published: 07 Apr, 2020

Citation: Aliyev NA, Aliyev ZN, Aliyeva SE (2020) Epileptic Personality Changes and Their Therapy. J Neurol Neurobiol 6(2): dx.doi.org/10.16966/23797150.163

Copyright: (C) 2020 Aliyev NA, et al. This is an open-access article distributed under the terms of the Creative Commons Attribution License, which permits unrestricted use, distribution, and reproduction in any medium, provided the original author and source are credited.

\section{Annotation}

The study was carried out by a prospective method, as well as randomized, that is, patients were examined as they applied to the Center for Mental Health of the Ministry of Health of the Republic of Azerbaijan. The main purpose of this article was to describe the diagnosis and treatment of personality changes in epilepsy. To this end, the article presents a phenomenological analysis of personality changes observed in 512 patients with various types of epilepsy for the period from 2015 to the first half of 2019. The importance of the data obtained for psychiatry is indicated and the corresponding recommendations for therapy are given.

Keywords: Epileptic personality changes; Diagnostics; Clinical picture; Therapy

\section{Introduction}

In medicine, no illness has been known as much as epilepsy. Thus, 41 names can be found in the literature. The most common of these are "holy disease", "Hercules disease", "Christ's punishment", "disease of the genius", "divine disease", "devil disease", "moon disease", "malignant disease", "Trembling", "agonizing pain" and so on, such as disease names. For the first time, the name of the disease was named Abu Ali Ibn Sina (Avisenna) (9801037). As well as epilepsy is derived from ancient greek verb epilambanein meaning to seize, take hold of or attack an information important because is based on personality changes. Epilepsy significantly affects a person's health, or to some extent, changes his or her personality. It is known that the symptoms that occur during epilepsy are generally divided into two groups: paroxysmal and persistent. Epileptic personality changes are considered one of the most complex and controversial probes of epileptology. Thus, some muscle fibers consider the epileptic nature to be pathognomonic for epilepsy, while others completely deny the existence of these changes.

The patients gave their informed, written consent to participate. In accordance with the Helsinki Declaration of the World Medical Association "Recommendations for doctors engaged in biomedical research involving people", adopted by the $18^{\text {th }}$ World Medical Assembly (Finland, 1964, revised in Japan in 1975, Italy-1983, Hong Kong- 1989, the South African Republic-1996, Edinburgh-2000); The Constitution of the Republic of Azerbaijan, the Law "On Psychiatric Assistance" (adopted on 12.06.2001, with amendments and additions-11.11.2011, Decisions of the Cabinet of Ministers of the Republic of Azerbaijan No. 83, dated April 30, 2010. "On Approval of the Rules for Conducting Scientific, Preclinical and Clinical studies of medicines" are established. The conditions of the conducted researches corresponded to the generally accepted norms of morality, the requirements of ethical and legal norms, as well as the rights, interests and personal dignity of the participants of the studies were observed.

Epilepsy significantly affects a person's health, or to some extent, changes his or her personality. Due to the inaccuracy of the term epileptic personality, some researchers view it as a non-hypoxic or psychotic disorder that does not reach the degree of total mental retardation. N.W. Cannabih (1938): Based on a number of premorbid traits of personality, patterns and dynamics of psychopathological stigma, we are currently diagnosing epilepsy without epileptic ulceration. We can safely say that we can see epilepsy cyanosis that many neurologists have not yet seen."

The above facts indicate that the epilepsy of personality changes has not been adequately prepared and up to date so far. All of this demonstrates the non-specificity of scientific opinions regarding the nature of personality traits in epilepsy and demonstrates the need for new research in this area. In this regard, the aim of the study was to study the psychopathological and clinical characteristics of personality changes during epilepsy.

\section{Research Materials and Methods}


Clinical psychopathology and clinical dynamic research methods have been used to determine the classification, dynamics and prognosis of mental disorders. To determine the level of excitement, SpielbergerHanin used the BasDarki questionnaire to determine the degree of aggression.

The Mental Health Center of the Ministry of Health also examined 512 patients suffering from various forms of epilepsy from 2015 to the first half of 2019. The age of the larval examined was 1850 years. The duration of the disease varied from 815 years. Observational forms of epilepsy given in table 1.

\section{Results}

In most patients the incidence is between 5 and 15 years ( $40 \%$ and $60 \%$, respectively). The onset of the disease was mainly pre-school and school age. Clinical analyzes of the mental field of patients are listed below.

\section{Thought breaches. Declining mentality of the mind}

As the declining mentality diminishes, it becomes more difficult to move from one idea to another, with persistence, repetition, and longterm fixation on the previous association. Speech and action are also torpid. The level of cognition is reduced and the speech becomes poor (oligophasia). This disorder of thinking is found in epilepsy.

\section{Emotional disorders. Violations of emotion dynamics}

Unsolicited emotions: It is desirable to replace one another with unnecessary, sometimes arbitrary, and often contradictory emotions.

Motivation (inertia, rigidity): Sticking to an emotion by ignoring the cause of long-lasting emotion. Personality caused by epilepsy is part of cornea and psycho organic syndrome.

Nausea: The impossibility of emotion control, the power of the will, is impossible. Reduction of emotional resonance -decrease in the intensity (distribution) of emotional reactions, narrowing their spectrum.

Emotional pathological inversion: The reduction of excessive emotional resonance is characterized by internal utilitarianism and the need to respond to needs.

Feeling less attentive: There is no focus and frequency of focus on a particular event or activity, there is difficulty in changing the direction of the target, sticking to it, pausing for an object or event for a long time. Poor distribution of attention. The lack of attention distribution is primarily due to the reduction of attention. The patient is unable to do two or more jobs at the same time. The patient is not able to figure out 7 out of 100 and tell them the number after each exit.

Table 1: Observational forms of Epilepsy.

\begin{tabular}{|l|c|}
\hline \multicolumn{1}{|c|}{ Controlled forms of epilepsy 2015-2019 years } & Total \\
\hline $\begin{array}{l}\text { G40.0 Localized (focal) (idiopathic) idiopathic epilepsy and } \\
\text { epileptic syndrome with focal onset irritation }\end{array}$ & 36 \\
\hline $\begin{array}{l}\text { G40.3 Generalized idiopathic epilepsy and epileptic } \\
\text { syndromes, abscess, myoclonic epilepsy }\end{array}$ & 302 \\
\hline G40.8 Other unspecified forms of epilepsy & 174 \\
\hline Women & 347 \\
\hline Men & 165 \\
\hline SELECTED TOTAL & 512 \\
\hline
\end{tabular}

Disorders of attention in the form of stresses, hemispheres, and excesses of deviations are characteristic for asthenic conditions. In addition to those shown in organic asthenic conditions, there is a significant reduction in the volume of attention, inertia, and low fatigue.

During the epilepsy, psychoorganic syndrome (WalterBuuel's triad) is common: Cognitive impairment;

\section{Memory weakening \\ 2. Affective failure}

From mild to moderate personality changes in the types of psycho organic syndrome, exploitative, apathetic variants in acne, euphoric and severe personality disorders are predominant.

The symptoms of acute asthenia are manifested in the form of severe physical and mental exhaustion, irritable weakness, and hyperesthesia.

Expressive-nervousness, brutal and labile effects, poor adaptation fluctuations are revealed. The rise of euphoric morbidity, disorders and inclination. Apathetic aspiration, narrowing of interest, in difference to disorders and dismnesthetic disturbances.

In 50 of the individuals surveyed, the psychometric scale of BasDarky and Spielberger Hahn was used to determine the degree of anxiety and aggression. On the one hand, the results show that both epilepsy and personal and situational anxiety are high. On the other hand, patients who suffer from epilepsy have a higher incidence of physical aggression and anxiety than normal.

Based on the results of clinical psychopathology and psychometric measures obtained in the study, personality changes during epilepsy can be divided into three categories

1. Mild personality changes

2. Moderate personality changes

3. Changes in personality rates to heavy rates

Criteria for mild personality changes:

a) Slight violation of family adaptation

b) Slight violation of social adaptation

c) Slight cognitive impairment

d) Tend to irrigate quickly

e) Situational excitement

Mechanisms of moderate personality changes:

a) Moderate violations of family adaptation

b) Acknowledgment violation of social adaptation

c) Mild cognitive impairment

e) Physical aggression

e) Situational and mild personal excitement

Criteria for severe personality changes:

a) Severe violation of family adaptation

b) Severe violation of social adaptation

c) Severe cognitive disorders (deficit of cognitive potential)

d) Physical, indirect, verbal aggression, why tivism, feelings of guilt

e) Aggravated situation and personal excitement 
Table 2: Global, Regional and National Burden of Epilepsy, 1990-2016: Systematic Analysis for Global Disease Research.

\begin{tabular}{|c|c|c|c|c|c|c|}
\hline \multirow[b]{2}{*}{ Counts } & \multicolumn{2}{|r|}{ Deaths } & \multirow{2}{*}{$\begin{array}{l}\text { Prevalence } \\
2016 \text { counts }\end{array}$} & \multicolumn{3}{|c|}{ DALYs } \\
\hline & 2016 Counts & $\begin{array}{c}\text { Percentage change in age- } \\
\text { standardised rates, } \\
1990-2016\end{array}$ & & $\begin{array}{l}\text { Percentage change in } \\
\text { age-standardised rates } \\
\text { 1990-2016 }\end{array}$ & 2016 counts & $\begin{array}{c}\text { Percentage change in age- } \\
\text { standardised rates, } \\
1990-2016\end{array}$ \\
\hline Russia & 882 & $-54.9 \%$ & 288899 & $-8 \cdot 7 \%$ & 120960 & $-38 \cdot 4 \%$ \\
\hline Ukraine & 642 & $-10 \cdot 9 \%$ & 96320 & $-3 \cdot 6 \%$ & 56695 & $-14 \cdot 6 \%$ \\
\hline Uzbekistan & 1789 & $95 \cdot 6 \%$ & 146213 & $34 \cdot 2 \%$ & 141783 & $54 \cdot 4 \%$ \\
\hline Kazakhstan & 316 & $-2 \cdot 9 \%$ & 61571 & $6 \cdot 7 \%$ & 36654 & $-3 \cdot 3 \%$ \\
\hline Azerbaijan & 260 & $11 \cdot 3 \%$ & 38421 & $25 \cdot 5 \%$ & 26774 & $6 \cdot 8 \%$ \\
\hline Georgia & 40 & $-52 \cdot 6 \%$ & 13424 & $4 \cdot 5 \%$ & 6115 & $-28 \cdot 7 \%$ \\
\hline
\end{tabular}

In addition to the results of this study and literature review by the authors, the following are considered characteristic for severe personality disorders during epilepsy

1. Affect inertia

2. Adhesion

3. Low mentality of all mental activities, lack of transparency, conservative observance of habits, habits and habits

4. Excessive pedantry and accuracy

5. Inflated courtesy, flattery and restraint, respect and kindness in typical emotional fine textures of patients with epilepsy

6. Excessive attachment to people, situations, things, animals, "adherence"

7. Excessive egocentrism-my "I" is always in the center of the patients' attention, their expressions, themselves, their illnesses, old insults, feelings of revenge are always at the forefront

8. Anger, tendency to get irritated, aggression

\section{Discussion}

According to WHO, the cost of epilepsy in the European Region is estimated at $€ 20$ billion a year. WHO Global, Regional, and National Epilepsy Burden, 1990-2016. A systematic review of the global burden of chronic disease should be looked at in some of the post-Soviet countries' epilepsy indices, including Azerbaijan. From these data, it is clear that Azerbaijan is the most prevalent country of epilepsy in the South Caucasus. These include the number of epilepsy, the rate of growth, the percentage of death, and the DALYs (Table 2).

It is clear from their indicators [1-3].

As can be seen from this table, Global, Regional and National Burden of Epilepsy. As can be seen from this table, Global, Regional and National Burden of Epilepsy is among the post-Soviet republics. Especially these diggers look very bad in Uzbekistan and Azerbaijan. From these data, it is clear that Azerbaijan is the most prevalent country of epilepsy in the South Caucasus. These include the number of epilepsy, the rate of growth, the percentage of death, and the DALYs.

\section{The following hypotheses explain many of the causes of personality changes in epilepsy patients}

1. Constitutional Hypothesis-Explains epilepsy with inherited tendency. Organic hypothesis is the basis of epilepsy due to organ damage to the brain.
2. Local conditioned hypothesis-personality disorders are caused by limited organic brain damage (mainly get, preferably, nipple, amygdalhipokamp, etc).

3. Psychogenic Hypothesis-This hypothesis explains personality changes in epilepsy with the response of the individual and society to the disease.

4. Predictability hypothesis of epileptic process-Hypothesis that the cause of epileptic personality changes is that after 1015 years, the progression of the epilepsy is aggravated.

5. Hypothesis of personality changes related to the form of epilepsy.

\section{Conclusion}

Based on our research, we can conclude that generalized epileptics include sensitivity, rapid response, depression, self-confidence, and self-esteem rays that are characterized by when you are awakened, you have little to no contact with epilepsy, low levels of communication, stubbornness, loss of self-control, anosnosnosis, alcoholism, deviant circadian rhythm, etc., peculiar.

Adoption of epileptic personality changes hypothesis associated with nanoconjunctants-hypothesis that epileptic personality changes are associated with long-term anti-epileptic drugs. Of these drugs, first of all, barbiturates should be mentioned.

In our studies, the most common (i.e., $75 \%$ of cases) were moderate and severe personality changes during epilepsy.

Finally, our aim is to provide a general criterion for specific personality disorders (F60) in view of the current XBT10, with the difference in personality changes that occur during epilepsy. The general criteria for specific personality disorders include this category: severe personality disorders and severe deviations from the individual's behavior as a consequence of illness, injury or other acute brain damage or other mental disorders. These violations usually involve several areas of personality, almost always associated with great personal suffering and social devastation.

The limitation of our work: 1) A small number of patients; The limitation of our work: 1) It is necessary to use psychometric scales more; 2) Continue the development of therapy for epileptic personality changes.

The study has a great theoretical and practical importance. First, it will contribute to the early detection of epileptic personality changes. Second improve the lifestyle of patients with epilepsy.

\section{Funding and Other Support}

The article carried out by its own financial resource. 


\section{Conflict of Interest}

None

\section{Acknowledgments}

The authors would like to thank the team of doctors of the Republican Mental Health center.

\section{References}

1. GBD 2016 Epilepsy Collaborators (2019) Global, regional, and national burden of epilepsy, 1990-2016: a systematic analysis for the Global Burden of Disease Study 2016. Lancet Neurol 4: 357-375.

2. Trimble MR, Schmitz B (2002) The Neuropsychiatry of Epilepsy. $2^{\text {nd }}$ Edition, Cambridge University Press, Cambridge, United States 81106.

3. Brodie MJ, Besag F, Ettinger AB, Mula M, Gobbi G, et al. (2016) Epilepsy, Antiepileptic Drugs, and Aggression: an Evidence-Based Review. Pharmacol Rev 68: 563-602. 